\title{
MIXED IONIC AND ELECTRONIC CONDUCTIVITY IN POLYMERS
}

DOE/ER/ $45220--3$

Progress Report

DE92 008429

for Period January 1, 1989 - December 31, 1989

D. F. Shriver

Northwestern University

Evanston, IL 60208-3113

\begin{abstract}
NOTICE
This report was prepared as an account of work sponsored by the United States Government. Neither the United States nor the Department of Energy, nor any of their employees, nor any of their contractors, subcontractors, or their employees, makes any warranty, express or implied, or assumes any legal liability or responsibility for the accuracy, completeness, or usefulness of any information, apparatus, product or process disclosed or represents that its use would not infringe privately-owned rights.
\end{abstract}

June 1990

Prepared for

THE U. S. DEPARTMENT OF ENERGY

AGREEMENT NO. DE-FG02-85ER45220

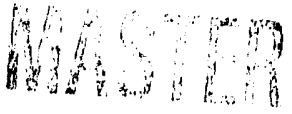

Se

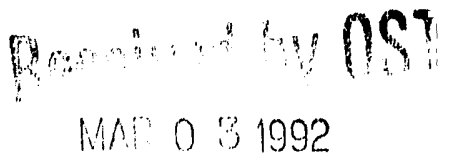




\begin{abstract}
The conductivity of iodine-containing polymers was investigated and conductivity along polyiodide chains is implicated by the concentration dependence of the conductivity data and spectroscopic measurements. On the theoretical side, entropy based models were developed to describe ion motion in polymers.
\end{abstract}

\title{
Progress
}

Our primary focus in the experimental program has been on the nature of polyiodidecontaining polymer electrolytes. These interesting materiais exhibit ohmic behavior associated with polyiodides and nonohmic behavior associated with the transport of cations and simple anions, in a polar host polymer. The two host polymers receiving most of our attention were MEEP, $+\mathrm{NP}\left(\mathrm{OC}_{2} \mathrm{H}_{4} \mathrm{OC}_{2} \mathrm{H}_{4}\left(\mathrm{CH}_{3}\right)_{2} \rightarrow_{n}\right.$, and atactic $\mathrm{PPO},+\mathrm{CH}\left(\mathrm{CH}_{3} \rightarrow-\mathrm{CH}_{2} \mathrm{O} \rightarrow_{n}\right.$. One major accomplishment was to map the conductivity surface for the ternary system, MEEP xNaI- $\mathrm{yI}_{2}$. This surface has a ridge in the conductivity corresponding to intermeciate concentrations of $\mathrm{NaI}$, emphasizing the central role of $\mathrm{I}_{n}{ }^{-}$formation in the electronic conductivity. Far infrared and Raman spectra substantiate the presence of polyiodides in these materials. In the course of these conductivity studies we discovered how to circumvent problems with electrode corrosion, which have interfered with previous measurements. We found that polyiodides result from the interaction of $\mathrm{I}_{2}$ with polyethers; apparently redox disproportionation of $I_{2}$ is responsible for this polyiodide generation. Currently, we are studying the nature of this reaction.

In another branch of our experimental research, we have initiated synthetic work on polypyrroles and polythiophenes with pendant polyether groups. When doped with alkali metals, these materials should exhibit mixed ionic and electronic conductivity.

The primary theoretical emphasis in this part year has been on the nature of ion pair 
formation. When mixed conductivity occurs, one major effect of the electronic carriers on the ions should be screening of the coulomb attraction, resulting in reduced formation of ion pairs and increased ionic conductivity. The ultimate challenge in this regard is development of a full frequency and wave vector dependent dielectric function, a project that we intend to begin in 1990. The dependencies of ion pair formation, however, should be the same in mixed conductors and in complex electrolytes. Important spectroscopic work by Torell and by us have indicated that the importance of ion pairing in fact increases with temperature; this observation is quite different from earlier reports from several groups in Grenoble. It is also consistent with the observation by Greenbaum that "salting out" occurs with increased temperature in various (PPO) electrolytes. Theoretical understanding of this increased formation with temperature seems similar to the problem of lower consolute temperatures in the classical physical chemistry of solutions.

We developed an entropy-based model to explain this behavior. Essentially, the entropy cost for breaking up an ion pair is positive in most cases, since the free ions, particularly the cation, will complex with the electrolyte and thus reduce very substantially the configurational entropy. Utilizing a simple lattice model, we have been able to predict both the change in ion pair formation with temperature and conditions under which ion pairs will in fact, either decrease or increase with increasing temperature. We feel that this is an important effort, since ion pair formation can substantially reduce overall conductivity in these materials.

\section{DOE Supported Publications 1989:}

"Synthesis, Characterization, and Electrical Response of Phosphazene Polyelectrolytes", S. Ganapathiappan, K. Chen and D. F. Shriver, JACS, 111, 4091 (1989).

"Polymeric Electrolytes and Polyelectrolytes: Salt Concentration and Domain Effects on Conductivity", M. A. Ratner, S. D. Druger and A. Nitzan, Mat. Res. Soc. Symp. Proc., 135, 13 (1989). 
"Fluctuations, Structure Factors and Correlations: Ionic Transport in Frameworks Electrolytes", M. A. Ratner and Y. Boughaleb, in Laskar and Chandra, eds., Superionic Solids and Solid Electrolytes: Recent Trends, Academic Press: 515 (1989). 

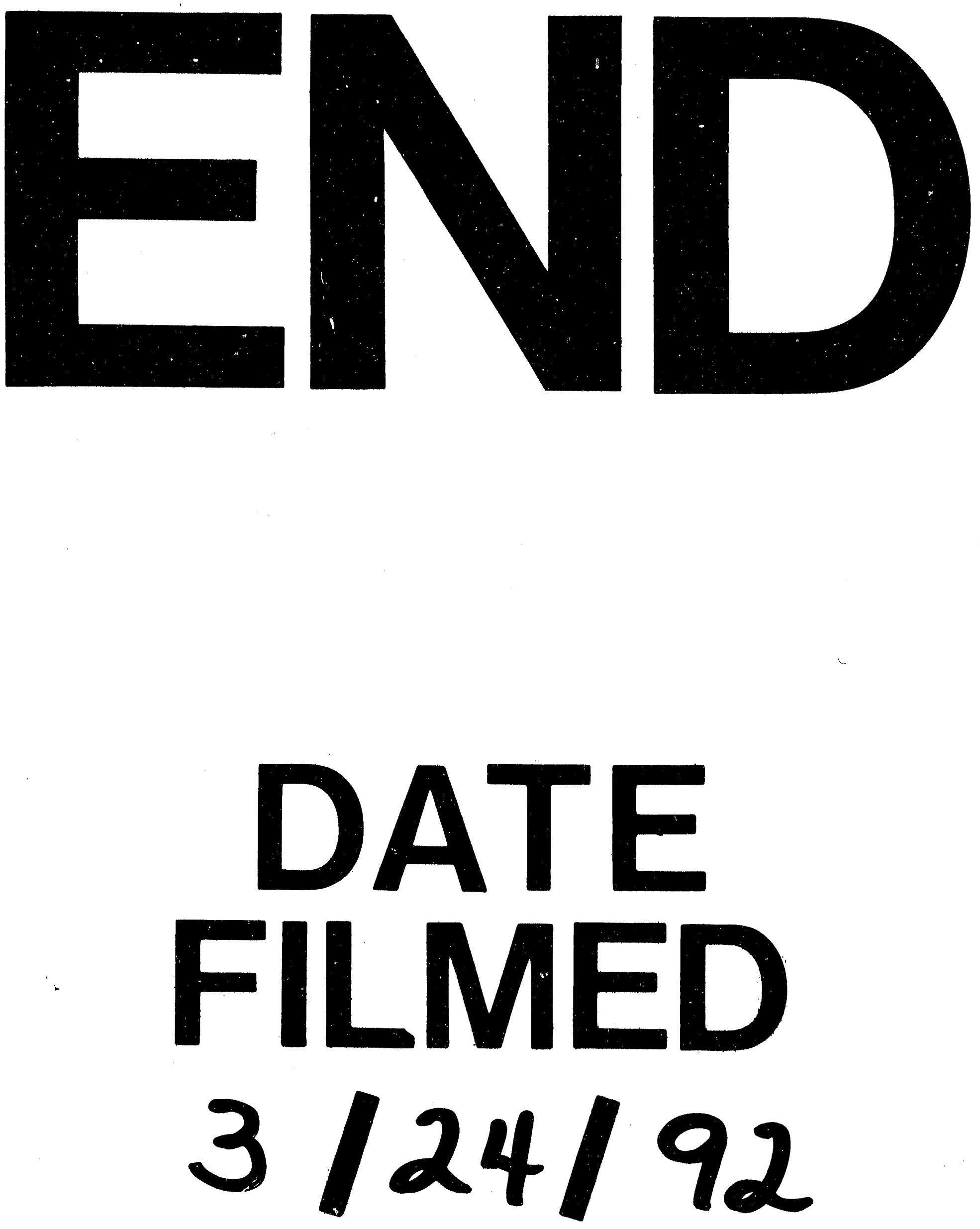
